\title{
Sport participation in Victoria, 2019 Research summary
}

This summary outlines key findings and insights from the 5th year of the VicHealth and Sport and Recreation Victoria's joint research project into organised community sport participation in Victoria. The report covers 10 popular sports and provides comparison in participation across age, sex and region in 2019 compared to 2015.

Figure 1. Sports included in the VicHealth and Sport and Recreation Victoria research

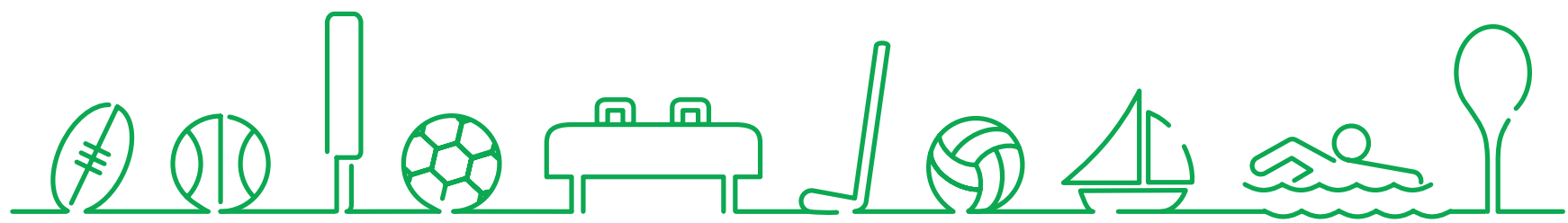

Please note: golf and bowls did not provide data for 2019 and are not included

Key findings at a glance: organised sport participation in Victoria, 2019

Over half of all sport participants are aged between $4-14$ years. Sport participation is highest among children and adolescents aged 10-14 years and drops significantly during late adolescence.
Sport participation is higher for males than females.
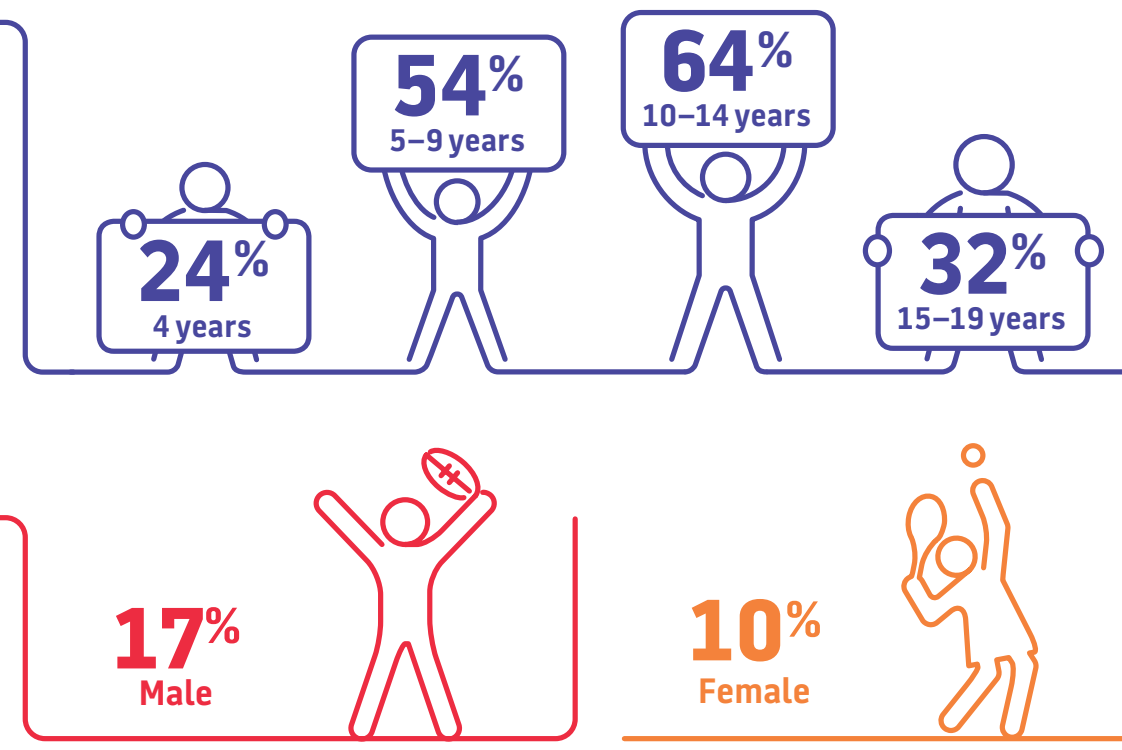

Sport participation rates are higher in regional Victoria compared to metropolitan Melbourne. Metropolitan-growth areas have considerably lower sport participation compared to all other regions.
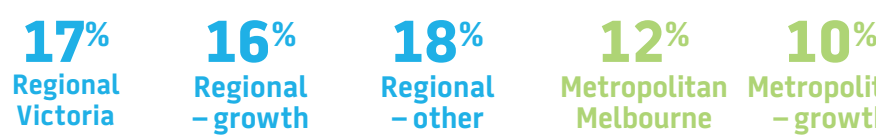

$13 \%$

Metropolitan Metropolitan Metropolitan Melbourne - growth - other
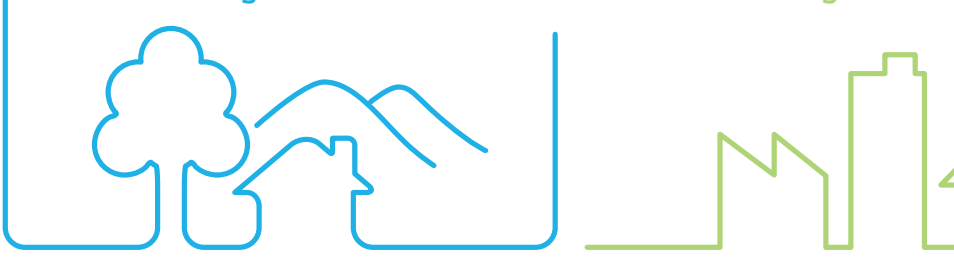

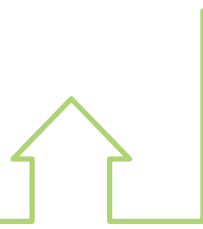




\section{Organised sport participation in 2019 compared to 2015}

Participation in sport increased by more than 119,000 participants ( $0.8 \%$ increase in the participation rate). The participation increase was over twice as high for females ( $1.1 \%$ increase) than males ( $0.5 \%$ increase).

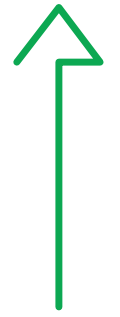

5 sports increase

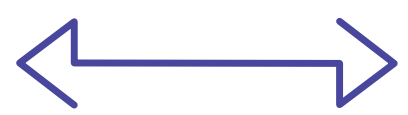

2 sports same

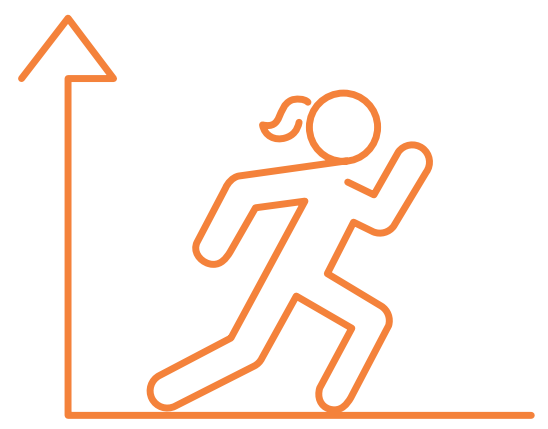

7 sports increased participation rate for females

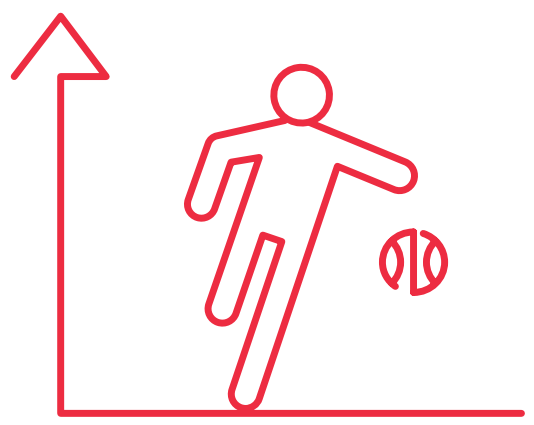

6 sports increased participation rate for males

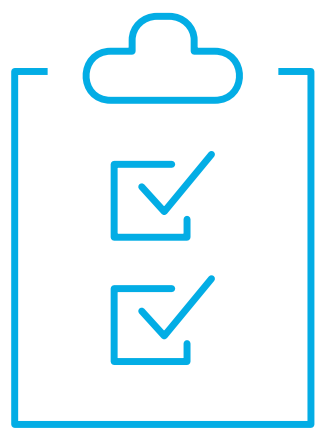

The overall participation numbers increased by 119,229 to a total of 868,266 participants in 2019.

This corresponds to a participation rate increase of $0.8 \%$. 


\section{$4 \%$ \\ 4 years}

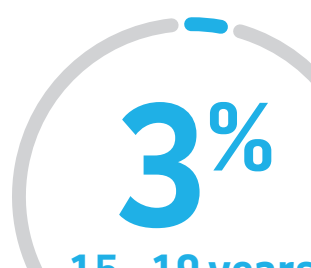

$15-19$ years
The largest growth in participation rates 2015-2019 were within the 4 year old age group (4\%) followed by the 15-19 year age group (3\%).

The growth in participation was largely due to an increase in female participation rates. Female participation rates grew across all age groups, however male participation rates declined for those aged 5-14 years.

For females, the largest growth was for 4 year olds (7\%), followed by 5-9 year olds (5\%), and 10-14 year olds (4\%).

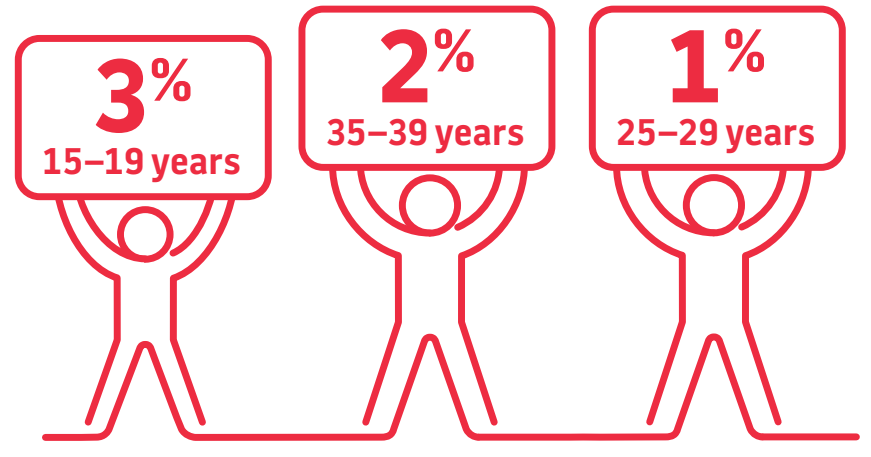

For males, the largest growth was for 15-19 year olds (3\%), followed by 35-39 year olds (2\%), and $25-29$ year olds (1\%).

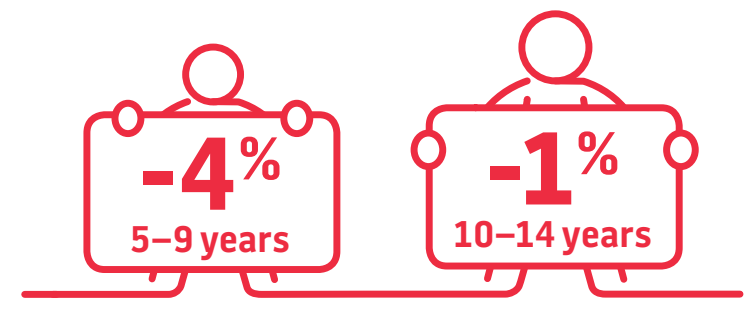

Male participation declined for $5-9$ year olds $(-4 \%)$ and $10-14$ year olds (-1\%). 


\section{Regional and local government snapshot}

There is considerable variation in overall participation rates in these sports across local government areas (Table 1). An understanding of how participation rates differ can inform local planning for facilities, programs and an overall approach to increasing physical activity. However, this information should be considered in conjunction with other available data to build a total picture of the needs of the local community. Lower participation rates do not necessarily mean the area has lower overall physical activity levels. It may mean, for instance, that there is a lack of sporting facilities and instead the community has higher rates of walking, cycling or other active recreation.

\section{Organised sport participation in Victoria, 2019}

- The highest overall sport participation rate was $31 \%$ in Buloke Shire, in the Regional- other area. The highest participation rates in the other areas were: Regional- growth: SurfCoast, 25\%; Metropolitan- other: Nillumbik 23\%; and Metropolitan-growth: Cardinia, 14\%.

- The lowest participation rate was 5\% in Greater Dandenong, in Metropolitan- other. The lowest participation in the other regions were: Metropolitan- growth: Melton, 8\%; Regionalother: Hepburn, 12\%: and Regional- growth: Moorabool, 15\%.

- The highest participation rate for females was 73\% for 10-14 year olds, within Regional- other, followed by $61 \%$ in Regional- growth, and 57\% for Metropolitan- other, but only $30 \%$ for Metropolitan-growth for the same age group.

- The highest participation for males was 93\% for 10-14 year olds, within Regional- other, followed by $85 \%$ in Regionalgrowth, and $77 \%$ for Metropolitan- other, but only $51 \%$ for Metropolitan- growth for the same age group.

- Within the regional LGAs, there was generally higher participation in the north-west and south-west compared to the eastern regions of Victoria.

- Within the metropolitan LGAs, there was generally higher participation in the eastern regions compared to western suburbs.

\section{Organised sport participation in 2019 compared to 2015}

- The region with the highest participation growth was Regional- growth with an overall increase of 3\%, followed by Metropolitan- other with an overall increase of $0.9 \%$, Regional- other $0.7 \%$ and Metropolitan- growth $0.2 \%$ increase. Male participation declined in Metropolitangrowth area.

- The largest increases in participation were in Regionalgrowth areas and an increase of $13 \%$ for females aged $5-9$, and $10 \%$ for those aged $10-14$ years. For males in these areas, participation increased $13 \%$ for those aged $10-14$, and $9 \%$ for those aged 15-19 years. 
Participation rates, 2019, Victoria: by age

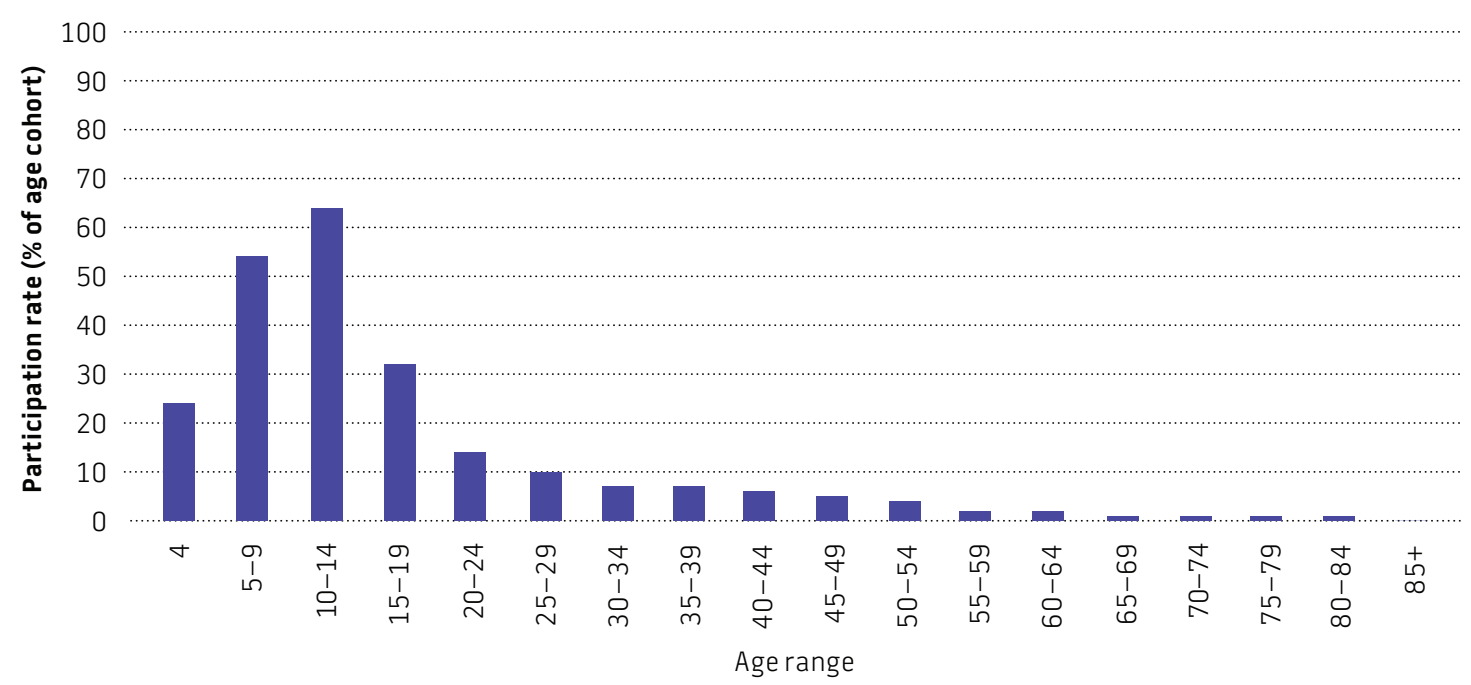

\section{Participation rates, 2019, Victoria: by sex and age}

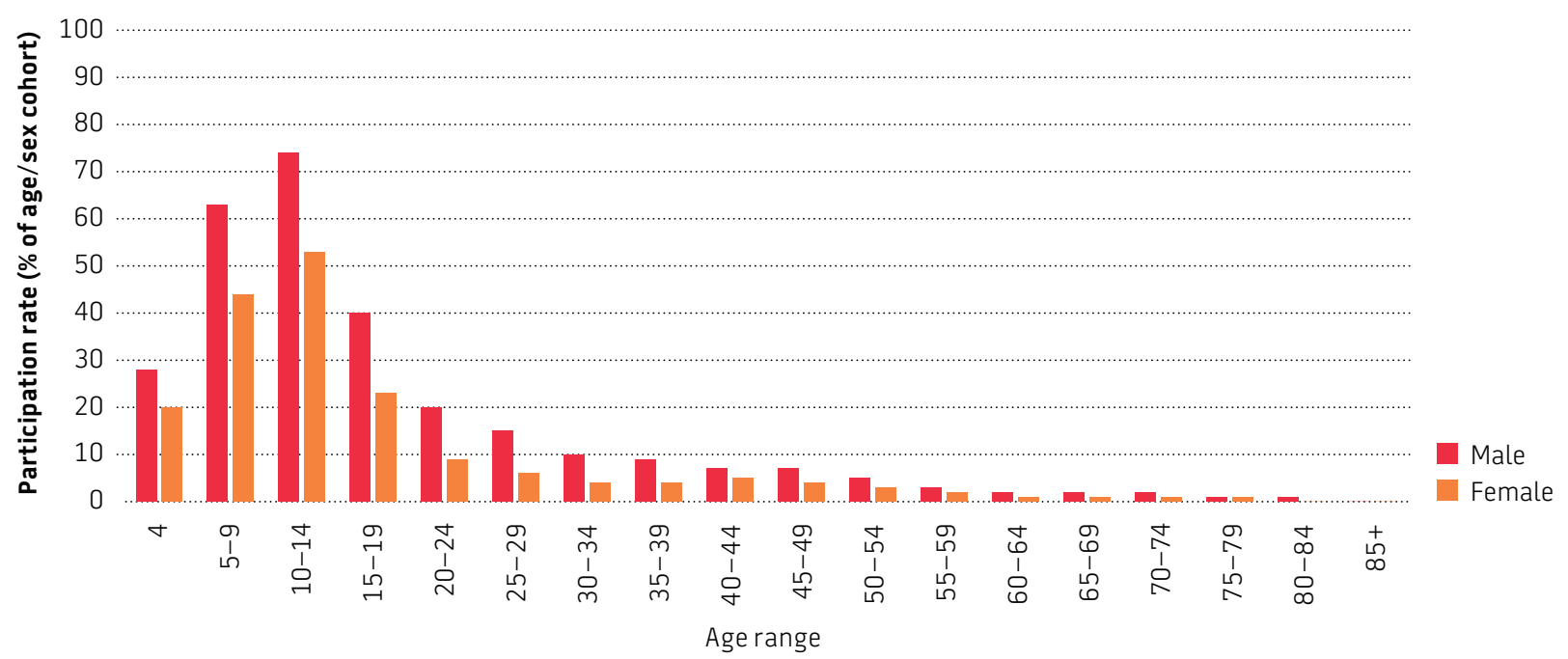

\section{Participation rates, 2019, Victoria: by region and age}
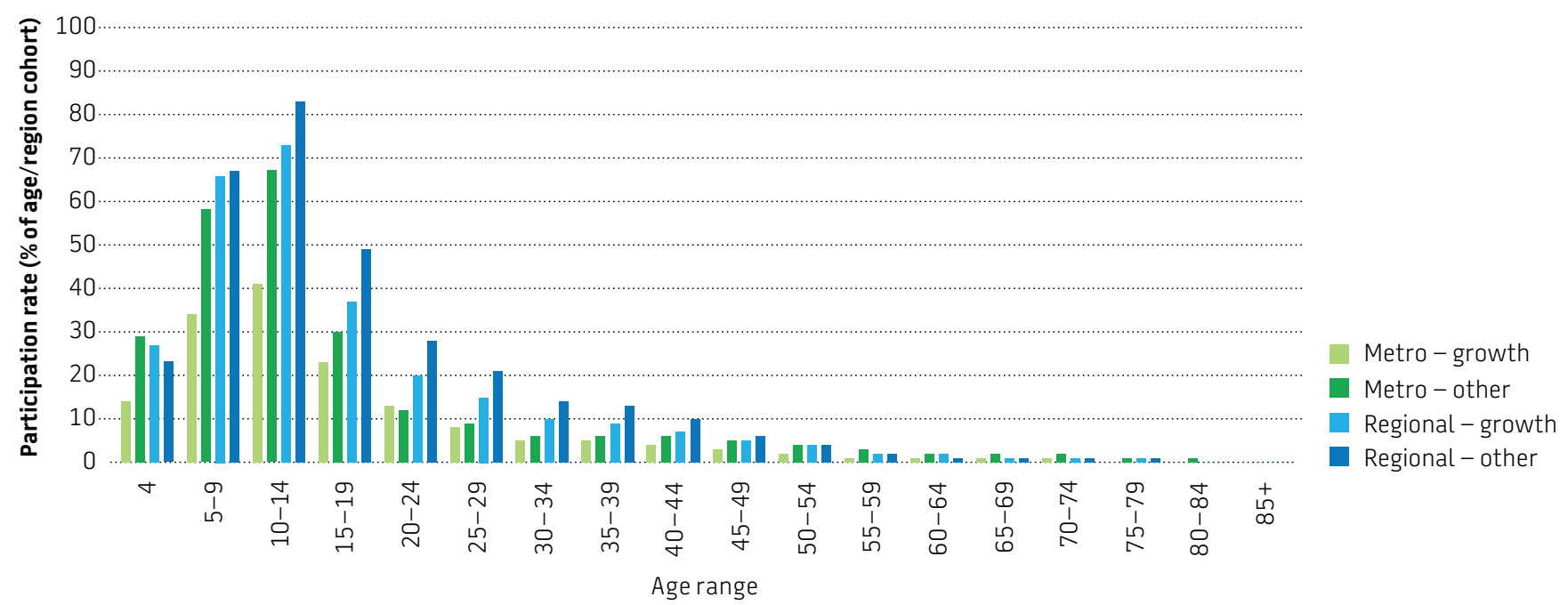
Participation numbers change, 2015, 2019 Victoria: by sex

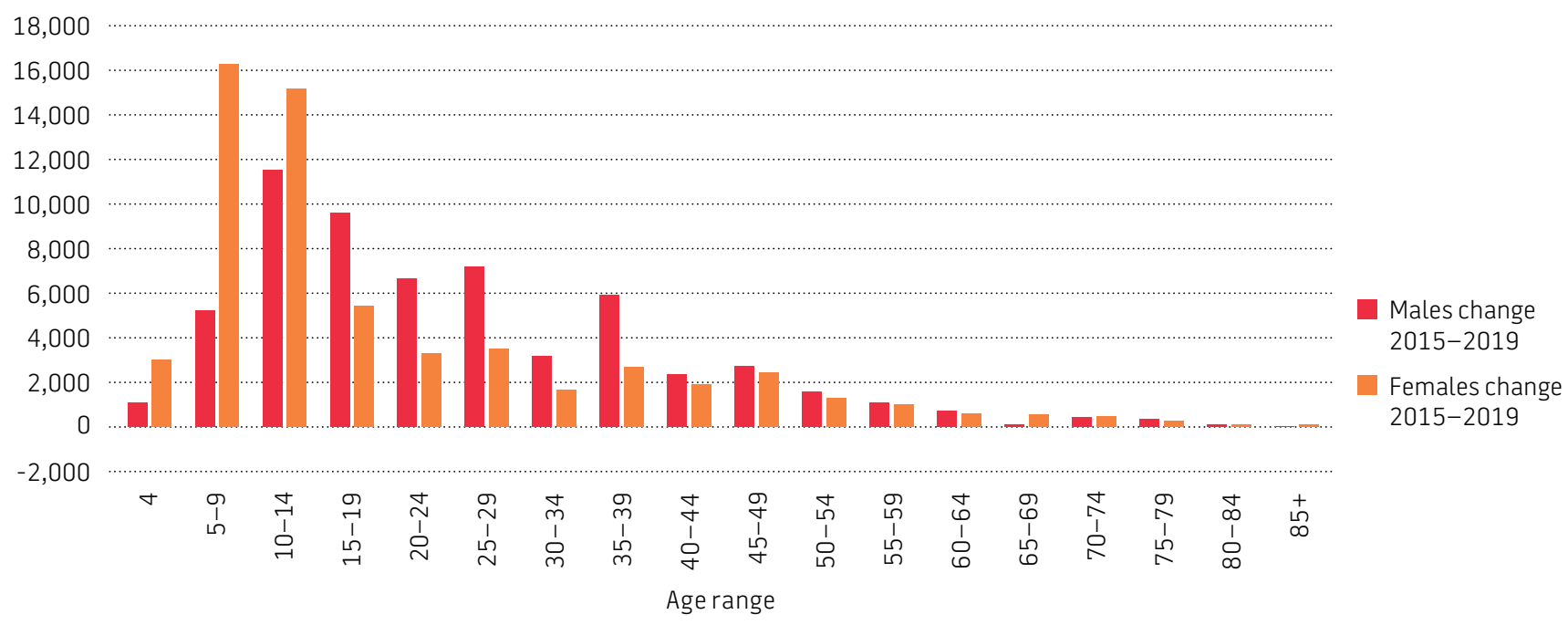

Participation rate change, 2015, 2019 Victoria: by sex

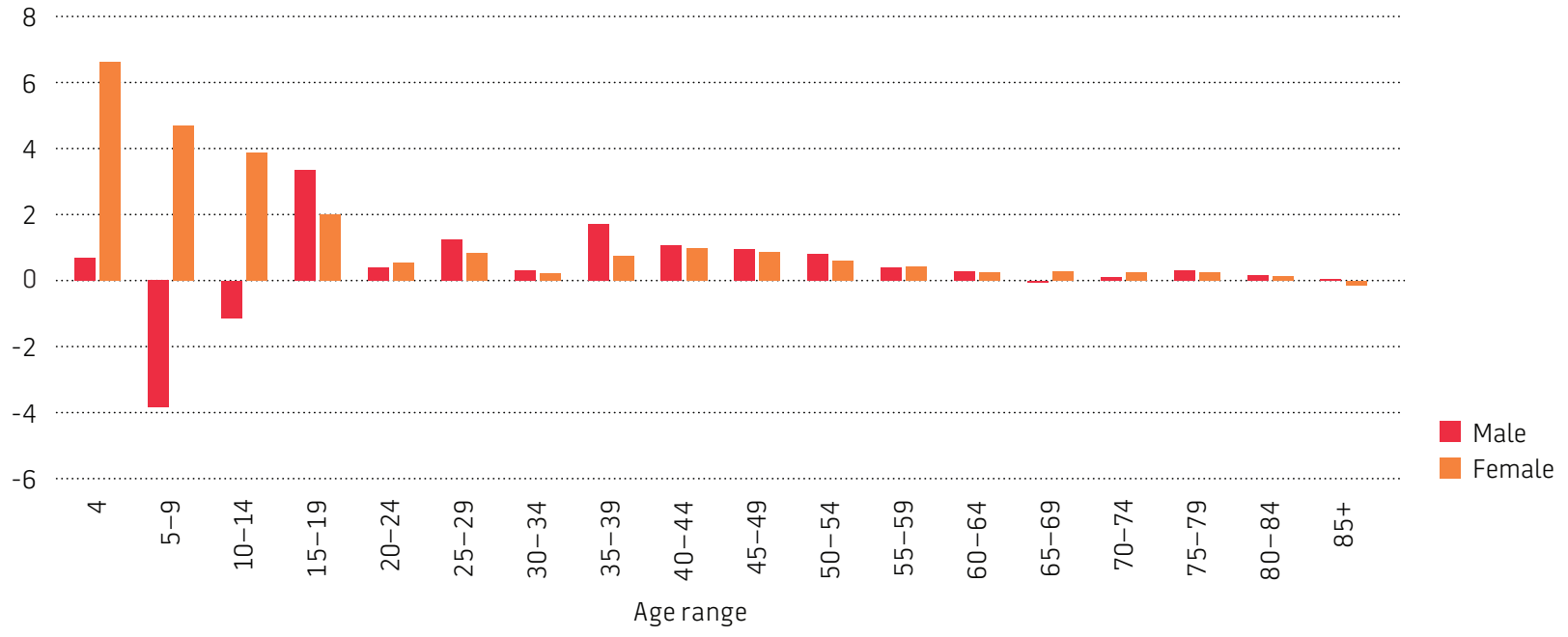


Participation rates, 2019, Victoria: by LGA

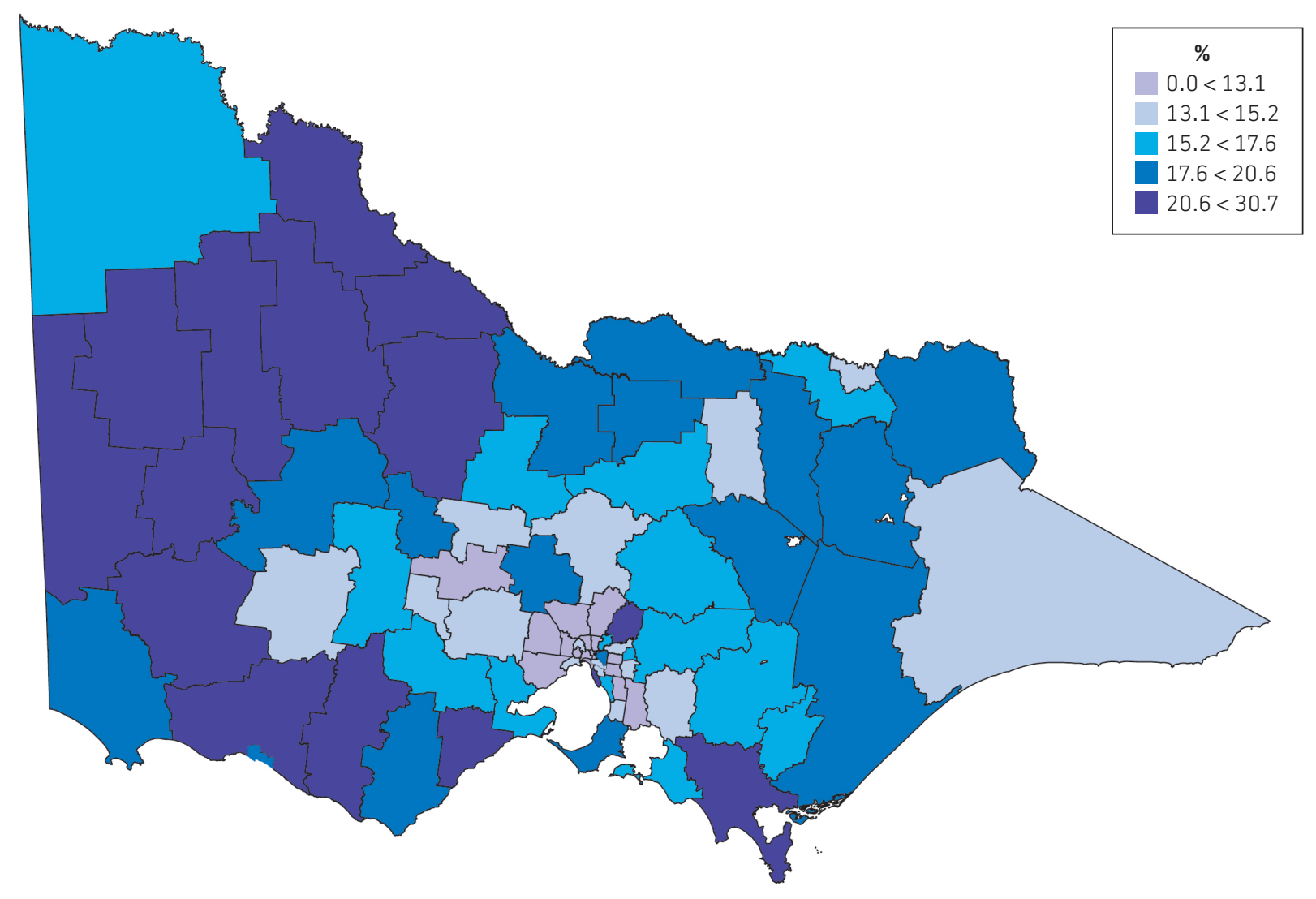

Participation rates, 2019, Metropolitan region: by LGA

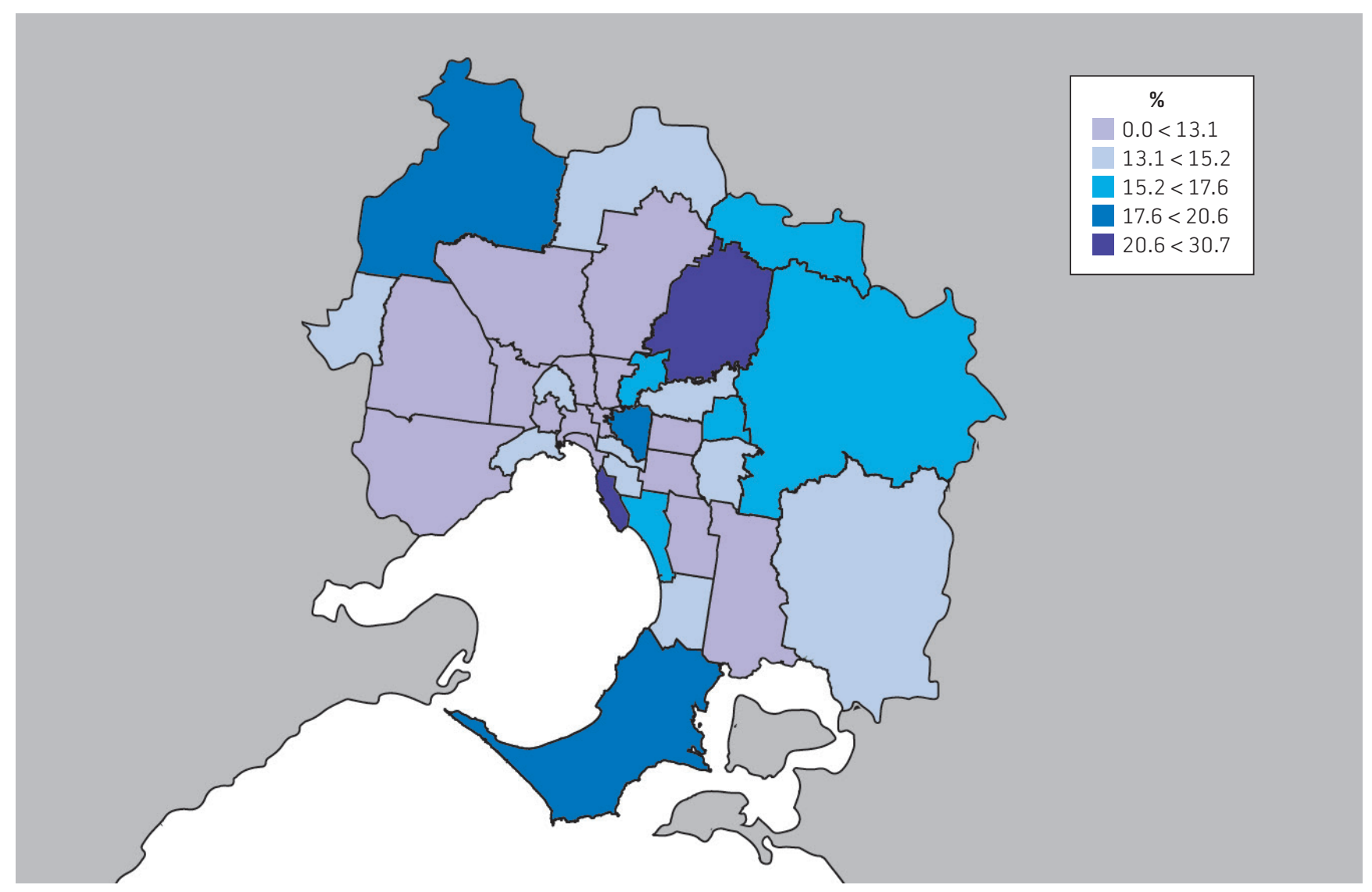


Table 1: Participation rates, 2019, Victoria: by Local Government Area

\begin{tabular}{|c|c|c|c|}
\hline LGA name & $\begin{array}{r}\text { Participation rate } \\
2019\end{array}$ & LGA name & $\begin{array}{r}\text { Participation rate }^{1} \\
2019\end{array}$ \\
\hline \multicolumn{2}{|l|}{ Metropolitan - growth } & \multicolumn{2}{|l|}{ Regional - other } \\
\hline Cardinia (S) & 14.3 & Alpine $(S)$ & 18.0 \\
\hline Casey (C) & 10.4 & Ararat (RC) & 14.4 \\
\hline Hume $(C)$ & 10.1 & Benalla (RC) & 13.8 \\
\hline Melton (S) & 8.3 & Buloke (S) & 30.7 \\
\hline Mitchell (S) & 13.5 & Campaspe (S) & 19.1 \\
\hline Whittlesea (C) & 9.8 & Central Goldfields (S) & 18.0 \\
\hline Wyndham (C) & 9.9 & Colac Otway (S) & 20.2 \\
\hline \multicolumn{2}{|l|}{ Metropolitan - other } & Corangamite (S) & 25.6 \\
\hline Banyule (C) & 16.5 & East Gippsland (S) & 14.6 \\
\hline Bayside (C) & 22.4 & Gannawarra(S) & 24.0 \\
\hline Boroondara (C) & 18.2 & Glenelg(S) & 19.8 \\
\hline Brimbank (C) & 6.5 & Golden Plains (S) & 17.0 \\
\hline Darebin (C) & 10.4 & Greater Shepparton (C) & 17.7 \\
\hline Frankston (C) & 14.9 & Hepburn (S) & 11.9 \\
\hline Glen Eira (C) & 14.1 & Hindmarsh (S) & 26.6 \\
\hline Greater Dandenong (C) & 5.4 & Horsham (RC) & 20.6 \\
\hline Hobsons Bay (C) & 13.4 & Indigo (S) & 17.0 \\
\hline Kingston (C) & 16.2 & Latrobe (C) & 15.8 \\
\hline Knox (C) & 14.5 & Loddon (S) & 23.8 \\
\hline Manningham (C) & 13.6 & Macedon Ranges (S) & 18.9 \\
\hline Maribyrnong (C) & 8.7 & Mansfield (S) & 18.2 \\
\hline Maroondah (C) & 15.7 & Mildura (RC) & 15.9 \\
\hline Melbourne (C) & 6.0 & Moira (S) & 18.9 \\
\hline Monash (C) & 9.7 & Mount Alexander (S) & 14.9 \\
\hline Moonee Valley (C) & 13.7 & Moyne (S) & 24.9 \\
\hline Moreland (C) & 9.3 & Murrindindi (S) & 15.3 \\
\hline Mornington Peninsula (S) & 18.0 & Northern Grampians (S) & 18.6 \\
\hline Nillumbik (S) & 23.3 & Pyrenees (S) & 17.1 \\
\hline Port Phillip (C) & 9.7 & Queenscliffe (B) & 29.2 \\
\hline Stonnington (C) & 14.4 & South Gippsland (S) & 21.7 \\
\hline Whitehorse (C) & 12.6 & Southern Grampians (S) & 25.7 \\
\hline Yarra (C) & 10.3 & Strathbogie (S) & 15.5 \\
\hline Yarra Ranges (S) & 16.6 & Swan Hill (RC) & 21.5 \\
\hline \multicolumn{2}{|l|}{ Regional - growth } & Towong (S) & 20.6 \\
\hline Ballarat (C) & 15.1 & Wangaratta (RC) & 18.0 \\
\hline Bass Coast $(S)$ & 16.0 & Warrnambool (C) & 17.6 \\
\hline Baw Baw (S) & 17.2 & Wellington (S) & 18.6 \\
\hline Greater Bendigo (C) & 17.1 & West Wimmera (S) & 20.8 \\
\hline Greater Geelong (C) & 15.3 & Wodonga (RC) & 14.1 \\
\hline Moorabool (S) & 14.8 & Yarriambiack (S) & 29.2 \\
\hline Surf Coast (S) & 25.0 & egend: $B$ = Borough & $y, S=$ Shire. \\
\hline
\end{tabular}

${ }^{1}$ Number of player registrations per 100 residents 


\section{Discussion}

\section{Overall message}

The longitudinal nature of this project with annual analysis and reporting has demonstrated clearly that with regards to participation in organised community sport, change can occur and is occurring. The 5 -year trends are demonstrating some positive changes.

At a population level, the most positive noticeable change has been an increase in female participation. Historically, female participation in organised sport has been considerably lower than males (Eime and Harvey 2018, Eime, Harvey et al. 2019) and while this is still the case, it is positive to see the gap in participation rates between males and females closing.

\section{Female growth}

The most promising growth has been in female participation, and particularly in male-dominated sports. This is directly aligned with the policy, investment and strategies developed and implemented by VicHealth, Sport and Recreation Victoria and the sports. Importantly for change to occur, this has included a holistic approach including a top-down and bottom-up methods.

There has been increased participation for females across all ages, and with high growth in participation rates for those aged 4-19 years. The highest growth has been for those aged 4 and 5-9 which is the entry age to many sports, through their modified sports programs (Eime, Casey et al. 2015).

The growth of female participation in sport, particularly in male-dominated sports will likely continue to impact sports clubs' capacity in terms of infrastructure as well as volunteers (Casey, Fowlie et al. 2019).

\section{Growth highest in young children and adolescents}

There was the highest growth in participation rates for both males and females aged 4 and during adolescence $15-19$ years. This is a positive sign as late adolescence is usually when the greatest decline occurs (Eime, Harvey et al. 2019, Eime, Harvey et al. 2020).

\section{Regional growth is high, but areas within metropolitan Melbourne are missing out}

The highest growth in participation rates was within the regional- growth areas of Victoria, and for females aged 5-19 followed by 10-14 years, and for males aged 10-14 followed by $15-19$, and $5-9$ years.

The majority of Victorian children play organised sport and participation is extremely high for those living in regional Victoria. However, many children and adolescents in Melbourne, particularly the metropolitan- growth areas are missing out.

Whilst participation numbers are increasing, the actual increase in overall participation rate is small. This is due to an increase in the population of Victoria which puts strain on sports club infrastructure and resources. 


\section{Recommendations for State Sporting Associations, sport policy makers and researchers}

\section{State Sporting Associations}

\section{Data collection}

That National Sporting Organisations and State Sporting Associations:

- Consider the continuity of participant data management systems so that individuals can be tracked over time.

- Capture additional demographic data of participants including those with a disability, culturally and linguistically diverse, and Aboriginal and Torres Strait Islanders.

- Continue to improve the data collection of social and recreational program participants.

- Use these research findings together with their individual sport participation reports to inform their strategic developments.

Participation

The State Sporting Associations develop and implement:

- Strategies that focus on retention of participants, particularly due to coronavirus and for females and adolescents.

- Clear player pathways for females in traditionally male-dominated sports.

- Social or recreational programs where possible.

- Strategies to incorporate skill development regardless of ability, age, gender or background.

- Specific and targeted policy and strategies to continue to increase female participation.

- Strategies related to improving health equity and increasing participation for specific demographic groups who face greater barriers for inclusion in sport, including those with a disability, culturally and linguistically diverse, Aboriginal and Torres Strait Islanders, people from low socioeconomic backgrounds, or areas where participation is low including Metropolitan - growth areas and specific LGAs.

- Strategies to accommodate growth in female participation in terms of club capacity of infrastructure and club volunteers.

\section{Sport policymakers and funding bodies}

\section{Data collection}

That policy makers and funding bodies:

- Continue data collection, analysis and reporting to inform evidence-based decisions across the sport sector, by sport and by specific demographic groups. Coronavirus will continue to impact sports for some time and will impact sports differently according to seasonality and other sport specific characteristics, as it will impact participants in different ways. Continuation of this project will allow the measurement of the impact of coronavirus on sport and the recovery of sport participation post-coronavirus and for different population demographic groups.
- Investigate the impact of coronavirus on sport volunteers.

- Support the collection of a wider scope of basic demographic information.

- Support the sport sector by developing a consistent set of additional demographic questions for sports to include within the participant registration systems.

- Make analysis and reporting from the research project more widely available to local councils and other relevant bodies.

\section{Participation}

That policy makers and funding bodies develop and implement strategies and policies to:

- Use the findings of the research project to inform their sport policy and strategic investments.

- Provide more opportunities for people from low socioeconomic backgrounds to play sport.

- Increase playing opportunities in a range of different formats including competition and other recreational or social formats.

- Continue to increase female participation.

- Increase participation in metropolitan - growth areas.

- Increase participation opportunities for specific demographic groups including those with a disability, culturally and linguistically diverse, and Aboriginal and Torres Strait Islanders.

- Accommodate growth in female participation in terms of club capacity of infrastructure and volunteers.

\section{Researchers}

That further research be conducted into:

- The impact of coronavirus on sport participation and club volunteers, by individual sports, and the sports sector more broadly.

- The contribution of participation in sport to individuals physical, social and mental health.

- The transition of female participants into traditional male-dominated sports.

Note: All recommendations should take into account the impact of coronavirus restrictions, which came into place in 2020 after this data capture and analysis, and remain in place at the time of publication. 


\section{About this research}

The Sport Participation Research Project has involved the analysis of data on organised sport participation in 12 major sports annually since 2015 . For 2019,2 sports (golf and bowls) were unable to provide their participant data. Therefore, this report integrates and summarises sport participation across 10 major sports and from 2015 to 2019.

This project reports on participation levels (numbers of registered participants and participation rates per head of population) and participation trends, for the Victoria population as a whole, and for various population segments.

The project aims to provide a reliable measure of organised sport participation in Victoria to inform planning, decision making and investments for State Sporting Associations, all levels of government, funding bodies and sport participation promoters, particularly relating to participation initiatives and facility planning.

\section{References}

Casey, M., J. Fowlie, M. Charity, J. Harvey and R. Eime (2019). "The implications of female sport policy developments for the community-level sport sector: a perspective from Victoria, Australia." International Journal of Sport Policy and Politics: 1-22.

Eime, R. and J. Harvey (2018). Sport participation across the lifespan: Australian trends and policy implications. Sport and physical activity across the lifespan. R. Dionigi and M. Gard. UK, Palgrave Macmillan: 23-43.

Eime, R., J. Harvey, M. Charity and H. Westerbeek (2020). "Longitudinal Trends in Sport Participation and Retention of Women and Girls." Frontiers in Sports and Active Living 2(39).

Eime, R. M., M. M. Casey, J. T. Harvey, M. J. Charity, J. A. Young and W. R. Payne (2015). "Participation in modified sports programs: A longitudinal study of children's transition to club sport competition." BMC Public Health 15(649): 7.

Eime, R. M., J. T. Harvey and M. J. Charity (2019). "Sport dropout during adolescence: is it real, or an artefact of sampling behaviour?" International Journal of Sport Policy and Politics 11(4): 1-12.

\section{ACKNOWLEDGEMENTS}

The Sport Participation Research Project 2019-2021 is funded by VicHealth and Sport and Recreation Victoria and is conducted by Professor Rochelle Eime, Ms Melanie Charity, Professor Hans Westerbeek, Dr Aurelie Pankowiak and Dr Jack Harvey (Victoria University and Federation University).

\section{www.sportandrecreationspatial.com.au}

The State Sporting Associations involved with this research are: AFL Victoria, Australian Sailing (Victoria), Basketball Victoria, Bowls Victoria, Cricket Victoria, Football Victoria, Golf Victoria, Gymnastics Victoria, Hockey Victoria, Netball Victoria, Swimming Victoria, and Tennis Victoria.

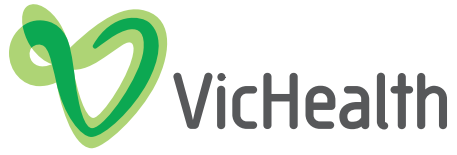

Victorian Health Promotion Foundation P0 Box 154 Carlton South Victoria 3053 Australia

$T+61396671333 F+61396671375$

vichealth@vichealth.vic.gov.au vichealth.vic.gov.au twitter.com/vichealth facebook.com/vichealth

VicHealth is committed to health equity, which means levelling the playing field between people who can easily access good health and people who face barriers, to achieve the highest level of health for everyone.

VicHealth acknowledges the support of the Victorian Government.

(c) VicHealth

March 2021

https://doi.org/10.37309/2021.PA1021

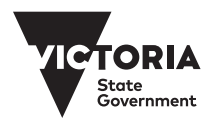

VicHealth acknowledges the Traditional Custodians of the land. We pay our respects to all Elders past, present and future. 